\title{
Impact of mixing and chemical change on ozone-tracer relations in the polar vortex
}

\author{
R. Müller ${ }^{1}$, S. Tilmes ${ }^{1,}{ }^{*}$, P. Konopka ${ }^{1}$, J.-U. Grooß ${ }^{1}$, and H.-J. Jost ${ }^{2}$ \\ ${ }^{1}$ ICG I, Forschungszentrum Jülich, 52425 Jülich, Germany \\ ${ }^{2}$ Bay Area Environmental Research Institute, Sonoma, CA, USA \\ *now at: ACD, NCAR, Boulder, CO, USA
}

Received: 8 June 2005 - Published in Atmos. Chem. Phys. Discuss.: 10 August 2005

Revised: 4 November 2005 - Accepted: 7 November 2005 - Published: 23 November 2005

\begin{abstract}
Tracer-tracer relations have been used for a long time to separate physico-chemical change from change caused by transport processes. In particular, for more than a decade, ozone-tracer relations have been used to quantify chemical ozone loss in the polar vortex. The application of ozone-tracer relations for quantifying ozone loss relies on two hypotheses: that a compact ozone-tracer relation is established in the 'early' polar vortex and that any change of the ozone-tracer relation in the vortex over the course of winter is caused predominantly by chemical ozone loss. Here, we revisit this issue by analysing various sets of measurements and the results from several models. We find that mixing across the polar vortex edge impacts ozone-tracer relations in a way that may solely lead to an 'underestimation' of chemical ozone loss and not to an overestimation. Further, differential descent in the vortex and internal mixing has only a negligible impact on ozone loss estimates. Moreover, the representation of mixing in three-dimensional atmospheric models can have a substantial impact on the development of tracer relations in the model. Rather compact ozonetracer relations develop - in agreement with observations in the vortex of a Lagrangian model (CLaMS) where mixing is anisotropic and driven by the deformation of the flow. We conclude that, if a reliable 'early vortex' reference can be obtained and if vortex measurements are separated from mid-latitude measurements, ozone-tracer relations constitute a reliable tool for the quantitative determination of chemical ozone loss in the polar vortex.
\end{abstract}

\section{Introduction}

In the stratosphere, compact relations are expected between tracers for which quasi-horizontal mixing along isentropes

Correspondence to: R. Müller

(ro.mueller@fz-juelich.de) is fast compared to their local chemical lifetimes (Plumb and Ko, 1992). This fact has been exploited in a variety of studies addressing a wide range of stratospheric research issues (e.g., Roach, 1962; Fahey et al., 1990; Volk et al., 1996; Sankey and Shepherd, 2003, and references therein). Further, it has been suggested that observed tracer-tracer relations can be used as a tool for the validation of chemistry climate models (Proffitt et al., 2003; Khosrawi et al., 2004) since the results of such models are otherwise difficult to compare with observations.

As long as a strong polar vortex exists, compact relations are also expected for the air mass inside the polar vortex. In particular, as (in the absence of halogen-catalysed chemical loss) ozone in the winter polar vortex can be considered long-lived (e.g., Proffitt et al., 1992; Sankey and Shepherd, 2003), compact ozone-tracer relations are expected for the polar vortex (e.g., Proffitt et al., 1993; Müller et al., 2001; Tilmes et al., 2004).

Therefore, tracer-tracer correlations (TRAC) have been used, for more than a decade now, to quantify chemical ozone loss in the polar vortices. Measurements from aircraft (Proffitt et al., 1990, 1993; Richard et al., 2001; Ross et al., 2004; Ulanovskii et al., 2004), satellites (Müller et al., 1996; Tilmes et al., 2003b, 2004), balloons (Müller et al., 2001; Salawitch et al., 2002; Vogel et al., 2003; Robinson et al., 2005), and from the Space Shuttle (Michelsen et al., 1998) were used for such analyses.

The TRAC methodology has been described in detail elsewhere (e.g., Proffitt et al., 1990; Müller et al., 1996, 2001; Salawitch et al., 2002; Tilmes, 2004; Tilmes et al., 2004). Briefly, an ozone-tracer relation that is established in the 'early' polar vortex will be unaltered ('frozen in') throughout the existence of the polar vortex in the absence of mixing and chemical ozone loss. In particular, diabatic descent inside the vortex alone cannot change an ozone-tracer relation.

Considering the change of ozone-tracer relations within the vortex for quantifying chemical ozone loss in the polar

(C) 2005 Author(s). This work is licensed under a Creative Commons License. 


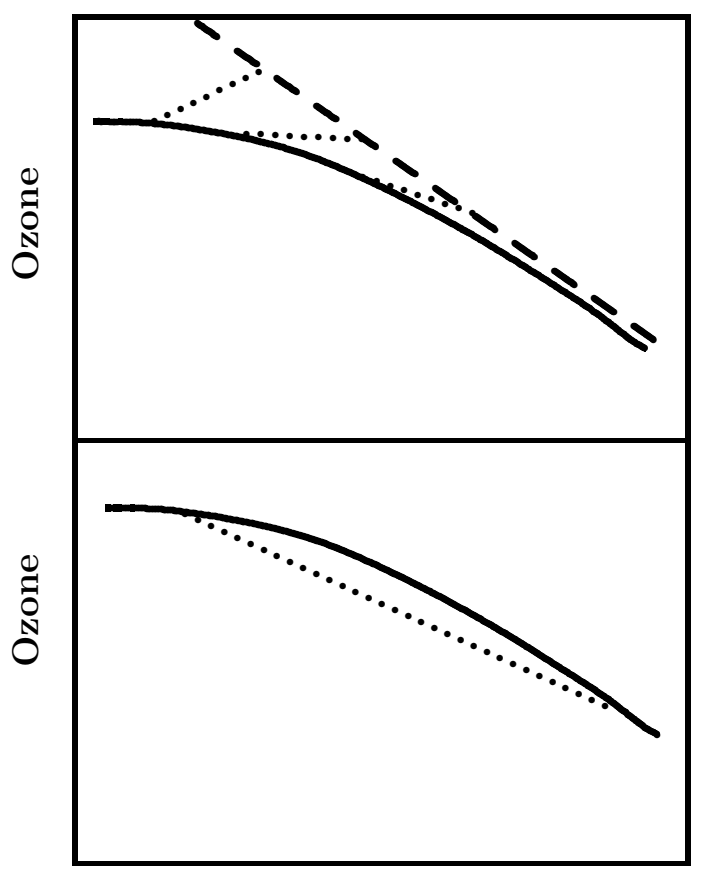

Tracer

Fig. 1. Schematic view of the impact of mixing on high-latitude ozone-tracer relationships. The solid line indicates a vortex ozonetracer relation, the dashed line a mid-latitude ozone-tracer relation, the dotted lines show possible mixing lines. Top panel shows the conditions for mixing across the vortex edge on isentropes. Note that there is a substantial difference in tracer mixing ratio between vortex and mid-latitude air masses on the same potential temperature level caused by the descent in the polar vortex. Bottom panel shows the conditions for mixing between two air parcels characterised by the same ozone-tracer relation.

vortex hinges on two hypotheses: First, that a compact ozone-tracer relation is established in the 'early' polar vortex, i.e., before the onset of chemical ozone loss. Second, that any change of the ozone-tracer relation in the vortex over the course of winter is caused predominantly by chemical ozone loss.

The validity of these hypotheses has been debated and the question was raised whether mixing across the vortex edge changes the ozone-tracer relation in a way that leads to an overestimate or an underestimate of ozone loss (e.g., Michelsen et al., 1998; Plumb et al., 2000; Müller et al., 2001; Salawitch et al., 2002; Rex et al., 2002; Sankey and Shepherd, 2003; Tilmes et al., 2003b, 2004). Indeed, the impact of mixing on tracer-tracer relationships was neglected in early studies using the TRAC methodology (e.g., Müller et al., 1996, 1997). However, over the course of winter and spring, the vortex air mass will be influenced to a certain extent by mixing in of air from outside the vortex. Inside and outside vortex air is characterised by different ozone-tracer relationships, with the outside vortex relationships showing greater ozone mixing ratios (and a stronger variability) for the same values of the tracer than inside relationships (e.g., Proffitt et al., 1990; Müller et al., 1999, 2002; Jost et al., 2002; Tilmes et al., 2003b). Therefore, if mixing occurs between air masses inside and outside the vortex, it will lead to points lying along the dotted mixing lines and thus above the original ozone-tracer relation in the vortex (Fig. 1, top panel). In contrast, mixing between two air masses that correspond to different points on the same non-linear, compact ozonetracer relation results in points that fall below the compact relation (Fig. 1, bottom panel).

Moreover, differential descent with subsequent mixing within the vortex impacts tracer-tracer relations. Although Ray et al. (2002) and Salawitch et al. (2002) conclude that the effect of differential descent increases the uncertainty of column ozone loss estimates by no more than $\approx 3-4 \%$ in Arctic winter 1999-2000, this mechanism could potentially have an influence on ozone loss estimates deduced using tracer-tracer relations.

Here, we revisit the question of the validity of the two major hypotheses on which the TRAC methodology is based. We consider the question of the compactness of the ozonetracer relation in the 'early' polar vortex. Further, we discuss the impact of mixing across the polar vortex edge on ozone loss estimates deduced using tracer-tracer relations and extend the discussion to the related issue of differential descent within the vortex. Finally, we examine the representation of ozone-tracer relations in a variety of models. We conclude that, if applied with care, ozone-tracer relations constitute a reliable tool for the quantitative determination of chemical ozone loss in the polar vortex.

\section{Reference ozone-tracer relations in the 'early' polar vortex}

\subsection{Reference relations constructed from mixing lines}

Michelsen et al. (1998) analysed ATMOS observations of ozone and $\mathrm{N}_{2} \mathrm{O}$ in the Arctic in March/April 1993. By considering the $\mathrm{O}_{3} / \mathrm{N}_{2} \mathrm{O}$ relationship they find that, on the same $\mathrm{N}_{2} \mathrm{O}$ level, much lower $(\approx 50-60 \%)$ ozone mixing ratios are observed inside compared to outside the polar vortex. Michelsen et al. (1998) interpret this difference between the out-of-vortex reference (blue line in Fig. 2) and the measurements inside the vortex as a signature of chemical ozone loss, but emphasise that chemical effects are unlikely to account for the entire difference. They also construct an alternative reference for the $\mathrm{O}_{3} / \mathrm{N}_{2} \mathrm{O}$ relation (the yellow line in their plate 4a, also shown in Fig. 2). This reference relation is constructed as a mixing line for a single mixing event (Fig. 1, bottom panel) and is derived by considering mixing in the $\mathrm{N}_{2} \mathrm{O} / \mathrm{CH}_{4}$ tracer space. However, it is unlikely that mixing of air between the two end-points of a mixing line that are separated by $\approx 25 \mathrm{~km}$ in altitude for an out-of-vortex 
profile (Michelsen et al., 1998, Plate 3) occurred in reality. Thus, this line should only be seen as an approximation to a reference relation that would develop by continuous mixing.

Comparing this reference with the March/April 1993 vortex observations from ATMOS, Michelsen et al. (1998) estimate only half of the ozone deficit that they deduce from an out-of-vortex reference. This finding is sometimes erroneously generalised to cases (e.g., Müller et al., 1996; Salawitch et al., 2002; Tilmes et al., 2004) where ozone-tracer relationships in the late vortex are compared with an "early vortex' reference (that is, a reference derived from observations made inside the vortex at a time before chemical ozone loss occurs) to deduce chemical ozone loss. Out-of-vortex ozonetracer relations are characterised by greater ozone mixing ratios for a given tracer value than vortex relations (Proffitt et al., 1993; Müller et al., 2001; Tilmes et al., 2004). Therefore, it is incorrect to interpret the finding of Michelsen et al. (1998) as 'mixing could produce about half the changes in the $\mathrm{O}_{3} / \mathrm{N}_{2} \mathrm{O}$ relation' (Plumb et al., 2000).

In Fig. 2, we compare the out-of-vortex measurements from ATMOS in April 1993 (blue line), the Michelsen et al. (1998) 'mixing reference' (the yellow line in their plate 4a shown here again as a yellow line) and the early vortex reference derived from HALOE early vortex measurements in 1992 (Tilmes et al., 2004, black line). Obviously, the latter reference and the best reference (yellow line) suggested by Michelsen et al. (1998) are in reasonable agreement. Certainly, they are closer to each other than any of the lines to the out-of-vortex ATMOS measurements. Therefore, ozone loss estimates deduced from these two references will be rather similar. Using the early vortex reference from Tilmes et al. (2004) yields an ozone loss of $117 \pm 17$ DU for April 1993 in the altitude range 380-550 K (corresponding to $1.4 \mathrm{ppm}<\mathrm{CH}_{4}<0.5 \mathrm{ppm}$ ), whereas employing the "mixing line reference' from Michelsen et al. (1998) yields an ozone loss of $98 \mathrm{DU}$, that is, only $16 \%$ less ozone loss than obtained from the Tilmes et al. (2004) reference. Nonetheless, long-range (in tracer space) mixing lines can only yield an approximation to the atmospheric conditions. Therefore, if used as reference relations for ozone loss estimates, mixing line references will be associated with a greater uncertainty than an early vortex reference deduced from measurements.

\subsection{Representation of ozone-tracer reference relations in models}

While classical two-dimensional models have been used in the past to study tracer-tracer relations (Plumb and Ko, 1992; Proffitt et al., 1992), today three-dimensional models are available for the simulation of transport and chemistry in the stratosphere. A particular advantage of three-dimensional models is that transport barriers in the stratosphere can be better represented than in two-dimensional models. The most important stratospheric transport barriers, the polar vortex edge and the subtropical barrier, are essential for the forma-

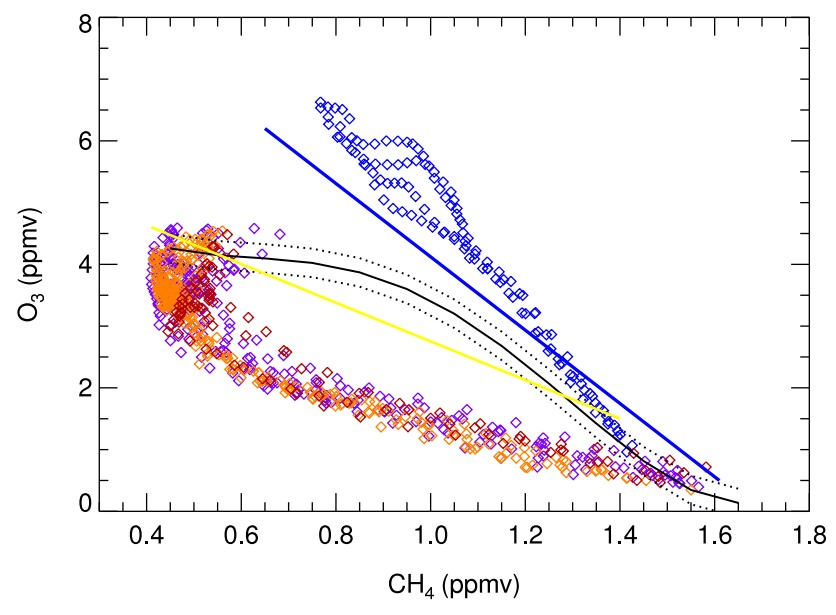

Fig. 2. Reference relations for the ozone-methane relation in the early vortex in winter 1992/93 from HALOE (Russell et al., 1993) and ATMOS (Michelsen et al., 1998). The black line shows the reference relation deduced from HALOE measurements in November 1992 in the early vortex, the dotted lines give the range of uncertainty (Tilmes et al., 2004). The yellow line shows the 'mixing line' reference estimated by Michelsen et al. (1998) based on ATMOS measurements, the solid blue line shows the out-of-vortex, highlatitude $\left(63^{\circ} \mathrm{N}-69^{\circ} \mathrm{N}\right)$, reference based on ATMOS measurements from 8-16 April 1993 (Michelsen et al., 1998). The ATMOS relations were converted from a $\mathrm{N}_{2} \mathrm{O} / \mathrm{O}_{3}$ relation to a $\mathrm{CH}_{4} / \mathrm{O}_{3}$ relation using the reported ATMOS $\mathrm{CH}_{4} / \mathrm{N}_{2} \mathrm{O}$ relation (Michelsen et al., 1998). Further shown are HALOE measurements inside the vortex in late March (purple diamonds), early April (orange diamonds), and late April 1993 (red diamonds). The blue diamonds indicate HALOE measurements in April 1993 in high latitudes outside the vortex.

tion of different compact tracer-tracer relations in the stratosphere (e.g., Michelsen et al., 1998; Plumb, 2002; Proffitt et al., 2003).

Nevertheless, even state-of-the-art three-dimensional models will misrepresent transport, and thus tracer-tracer relations, in some way. Depending on the numerical advection scheme employed, transport errors are introduced through numerical diffusion and dispersion (e.g., Rood, 1987; Müller, 1992). Dispersion errors that arise particularly strongly in centred difference and in spectral schemes, may lead to spurious scatter in simulations of nonlinear tracer-tracer relationships (Thuburn and McIntyre, 1997).

\subsubsection{Three-dimensional Chemistry Climate Models}

Recently, Sankey and Shepherd (2003) presented a thorough investigation of tracer relations in the stratosphere using the Canadian Middle Atmosphere Model (CMAM); they used a number of observed tracer-tracer relations to validate the model results. The model uses a (T32) spectral transport scheme with 50 layers in the vertical and a $\approx 3 \mathrm{~km}$ vertical resolution in the middle atmosphere. The vertical diffusion 


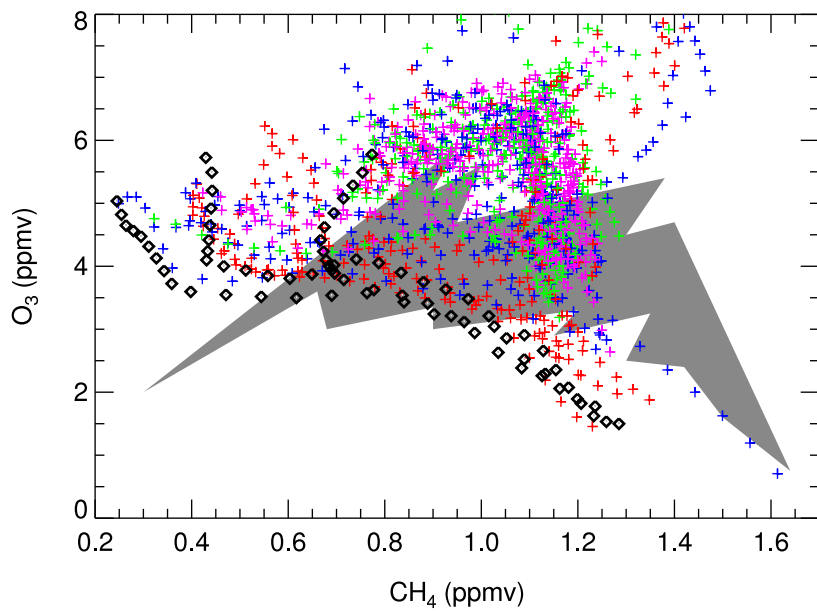

Fig. 3. The ozone-methane relation in the Northern hemisphere in January 1992. Shown are HALOE observations for the altitude range $10-100 \mathrm{hPa}$ for the period 10 to 14 January 1992 . The observations were made at equivalent latitudes of $25^{\circ}-40^{\circ} \mathrm{N}$ (purple symbols), $40^{\circ}-50^{\circ} \mathrm{N}$ (green symbols), $50^{\circ}-60^{\circ} \mathrm{N}$ (blue symbols), $60^{\circ}-65^{\circ} \mathrm{N}$ (red symbols). The black diamonds are observations inside the polar vortex according to the potential vorticity criterion of Tilmes (2004). The grey shaded area shows the range of CMAM model results for the vortex in a simulated January (Sankey and Shepherd, 2003). (The vortex is defined for the model results as potential vorticity greater than $400 \mathrm{PVU}$ at $10 \mathrm{hPa}$ ).

coefficient $K_{z z}$ is set to $1 \mathrm{~m}^{2} \mathrm{~s}^{-1}$. In the model simulations, distinct tracer-tracer relations develop in the tropics, the midlatitude surf zone, and in the Antarctic winter vortex in accordance with observations (e.g., Michelsen et al., 1998; Ray et al., 2002; Proffitt et al., 2003) and with the theoretical arguments of Plumb (2002).

However, the model is incapable of producing a strong polar vortex in the Arctic: 'there is virtually no barrier at all in the CMAM Arctic vortex' (Sankey and Shepherd, 2003). A transport barrier at the Arctic vortex edge (together with rapid mixing within the vortex) is the reason why compact tracer-tracer relations develop inside the polar vortex that are distinct from the tracer-tracer relations outside the vortex (e.g., Plumb, 2002). The segregation between compact tracer-tracer relationships inside and outside the vortex has been observed on many occasions (e.g., Proffitt et al., 1993; Michelsen et al., 1998; Müller et al., 1999; Ray et al., 2002; Tilmes et al., 2003b).

The formation of such a segregation of tracer-tracer relationships and the existence of a transport barrier at the edge of the Arctic vortex are the central assumptions for applying tracer-tracer relations to deduce chemical ozone loss inside the vortex (e.g., Müller et al., 1996; Tilmes, 2004). In the CMAM model, for Arctic conditions, these assumptions are not valid due to the the lack of a transport barrier at the edge of the Arctic vortex in CMAM. Consequently, by means of tracer-tracer relations it is not possible to deduce chemical ozone loss in the Arctic using CMAM results (Sankey and Shepherd, 2003). In the CMAM Antarctic vortex, for which a transport barrier is simulated, a compact ozone-tracer relation develops in the model. In CMAM it takes months for the compact correlation to develop; a truly compact correlation is established in August. A recent analysis of ILAS II measurements in Antarctic winter 2003 indicates that a compact relation had developed by the end of June (Tilmes et al., 2005b) (Tilmes et al., 2005a ${ }^{1}$ ). The fact that the simulated ozonetracer relation in the Antarctic vortex in CMAM does not resemble measurements by HALOE, ATMOS, and ILAS II (Müller et al., 1996; Michelsen et al., 1998; Tilmes et al., $2005 \mathrm{~b}$ ) is most likely due to an underestimate of halogencatalysed ozone depletion in the CMAM Antarctic vortex.

Sankey and Shepherd (2003) raised the question whether, given limited observations at a particular latitude, one could be under the false impression that a compact ozone-tracer relation exists, when in reality this is not the case. To illustrate their point, they consider (their Fig. 19) CMAM data for the $\mathrm{O}_{3} / \mathrm{CH}_{4}$ relation inside the polar vortex for 1 January. (The vortex being defined as a column of air with potential vorticity greater than $400 \mathrm{PVU}$ at $10 \mathrm{hPa}$, D. Sankey, pers. comm.). The CMAM model vortex is then sampled at the actual locations of HALOE measurements in January 1992. Due to the HALOE measurement geometry, these measurement locations rarely intercept the CMAM vortex. The CMAM $\mathrm{O}_{3} / \mathrm{CH}_{4}$ values at the HALOE measurement locations form a compact relation for $\mathrm{CH}_{4}$ lower than $\approx 1.3 \mathrm{ppm}$; for $\mathrm{CH}_{4}$ greater than $\approx 1.3 \mathrm{ppm}$, the $\mathrm{CMAM} \mathrm{O}_{3}$ values at the HALOE measurement locations show some scatter, albeit less scatter than all the CMAM vortex model points (Sankey and Shepherd, 2003). That is, if the real atmosphere were as simulated by CMAM, and had HALOE observed that model atmosphere during January 1992 the apparent correlation would have been the result of insufficient sampling. This thought experiment indicates the possible existence of a problem (Sankey and Shepherd, 2003).

To address the question whether such a problem might exist for conditions in the early polar vortex in the Arctic, we consider the actual HALOE measurements in mid-January 1992 (Fig. 3) colour-coded according to equivalent latitude. Based on the selection criteria of Tilmes et al. (2004), three HALOE measurements (black symbols in Fig. 3) are located in the polar vortex in January 1992. These profiles show a rather compact $\mathrm{O}_{3} / \mathrm{CH}_{4}$ relation, clearly more compact than the CMAM relation at the location of the HALOE measurements. Solely the HALOE measurements at top altitudes show characteristics of outside-vortex air. The observed $\mathrm{O}_{3} / \mathrm{CH}_{4}$ relation for outside-vortex, mid-latitude air

\footnotetext{
${ }^{1}$ Tilmes, S., Müller, R., Grooß, J.-U., Nakajima, H., and Sasano, Y.: Development of tracer relations and chemical ozone loss during the setup phase of the polar vortex, J. Geophys. Res., submitted, 2005a.
} 
shows considerable scatter, but always greater ozone values for a given tracer mixing ratio than the vortex air.

Further, measurements of the ILAS instrument (Sasano et al., 1999), which provides good coverage of the polar area in winter 1996-1997, demonstrate that a compact ozonetracer relation develops in the Arctic vortex which is clearly separated from the out-of-vortex relation (Tilmes et al., 2003b). The ILAS Arctic vortex measurements show no indication of a variability of the ozone-tracer relation resembling that in the CMAM model vortex. Also, HALOE measurements of the early spring vortex in years when HALOE provides good coverage of the polar area (e.g., early April 1992, 1995, 1996) show compact relations of both $\mathrm{HCl}$ and ozone with long-lived tracers (Müller et al., 1996; Tilmes et al., 2004).

In summary, the lack of a compact $\mathrm{O}_{3} / \mathrm{CH}_{4}$ relationship in the $\mathrm{CMAM}^{2}$ Arctic vortex could lead to the conclusion that compact correlations in the vortex may be deluded by insufficient sampling of the vortex air mass when in reality no such compact relation exits (Sankey and Shepherd, 2003). However, there is no evidence from measurements in the polar regions that such a problem occurs in reality.

\subsubsection{Three-dimensional chemistry transport models}

In the Chemical Lagrangian Model of the Stratosphere (CLaMS), advection and mixing are represented in a way that is very different from the transport schemes employed in Eulerian models. The mixing intensity in CLaMS can be controlled and is anisotropic in space and time (McKenna et al., 2002b; Konopka et al., 2004, 2005b). Due to these features, transport barriers can be represented particularly well in CLaMS.

For Arctic winter 2002/2003, Konopka et al. $(2005 \text { c })^{3}$ calculated the development over the course of the winter of passive ozone $\left(\mathrm{O}_{3}^{\text {pass }}\right)$ and $\mathrm{CH}_{4}$, both treated as purely transport quantities. The probability distribution function (PDF) for $\mathrm{O}_{3}^{\text {pass }}$ and $\mathrm{CH}_{4}$ on 11 January 2003 shows that a clear separation between mid-latitude and vortex air masses develops in the model (Fig. 4). The figure shows all CLaMS model points poleward of an equivalent latitude of $40^{\circ} \mathrm{N}$ between the $350 \mathrm{~K}$ and $700 \mathrm{~K}$ isentropes.

\footnotetext{
${ }^{2}$ Here shortcomings of the CMAM model are discussed that become apparent when the CMAM model results are compared in detail with measurements. The aim of this discussion is not to point to any particular weakness of the CMAM model; rather Sankey and Shepherd (2003) should be commended for conducting such a detailed comparison of results from a general circulation model with measurements.

3 Konopka, P., Engel, A., Funke, B., Müller, R., Grooß, J.-U., Günther, G., Wetter, T., Stiller, G., von Clarmann, T., Oelhaf, N. G. H., Wetzel, G., López-Puertas, M., Pirre, M., Huret, N., and Riese, M.: Ozone loss driven by nitrogen oxides and triggered by stratospheric warmings may outweigh the effect of halogens, Geophys. Res. Lett., submitted, 2005c.
}

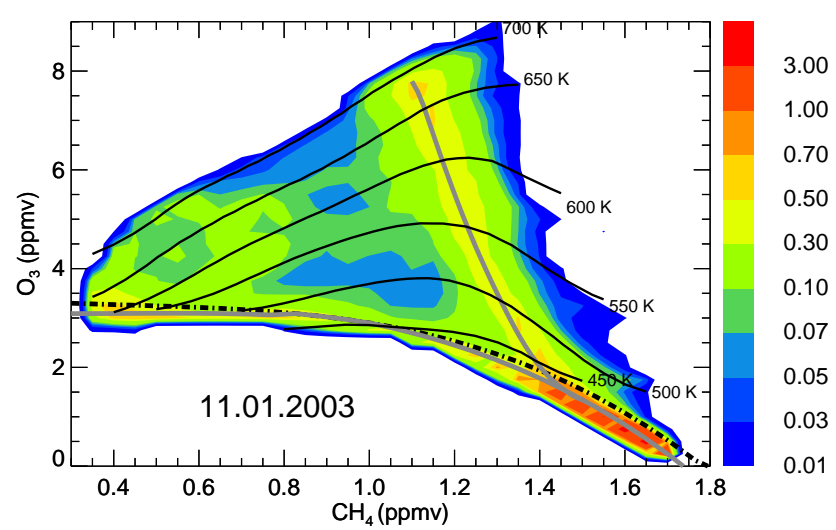

Fig. 4. The relation of passive ozone $\left(\mathrm{O}_{3}^{\text {pass }}\right)$ and $\mathrm{CH}_{4}$ on 11 January 2003 from model simulations (Konopka et al., 2005c ${ }^{3}$ ) of the Chemical Lagrangian Model of the Stratosphere (CLaMS). Shown are all CLaMS model points poleward of an equivalent latitude of $40^{\circ} \mathrm{N}$ between the $350 \mathrm{~K}$ and $700 \mathrm{~K}$ isentropes. The colour scale shows the probability distribution function (PDF) of $\mathrm{O}_{3}^{\text {pass }}$ and $\mathrm{CH}_{4}$; reference relations for vortex air and midlatitude air are shown as thick grey lines. For comparison, an early vortex reference relation (Tilmes et al., 2003a) deduced from MkIV measurements on 16 December 2002 is also shown (black dashed-dotted line). Also shown are approximate isolines of selected potential temperature levels. PDFs and potential temperature isolines were calculated for $\mathrm{O}_{3}^{\text {pass }}$ and $\mathrm{CH}_{4}$ bin sizes of 0.05 ppmv and 0.25 ppmv, respectively.

These CLaMS results suggest that in early January a transport barrier has formed in the model at the edge of the polar vortex leading to a separation between inside and outside tracer relations. Further, by that time, mixing within the vortex has homogenised the vortex air mass resulting in a compact ozone-tracer relation in the vortex.

The ozone-tracer relation in Eulerian chemical transport models has not been studied extensively. However, its has been shown that compact tracer-tracer relations can be simulated for the polar vortex by Eulerian chemical transport models (Plumb et al., 2000). Recently (Robinson et al., 2005) reported simulations with the SLIMCAT model, showing compact ozone/CFC-11 relations in agreement with balloonborne measurements.

\section{Impact of mixing on ozone-tracer relationships in the polar vortex}

\subsection{Impact of differential descent on tracer relations}

Differential descent of air masses within an otherwise isolated polar vortex may impact non-linear tracer-tracer relations for the vortex (Ray et al., 2002; Salawitch et al., 2002). Potentially, this mechanism could have an influence on ozone loss estimates deduced using tracer-tracer relations. 


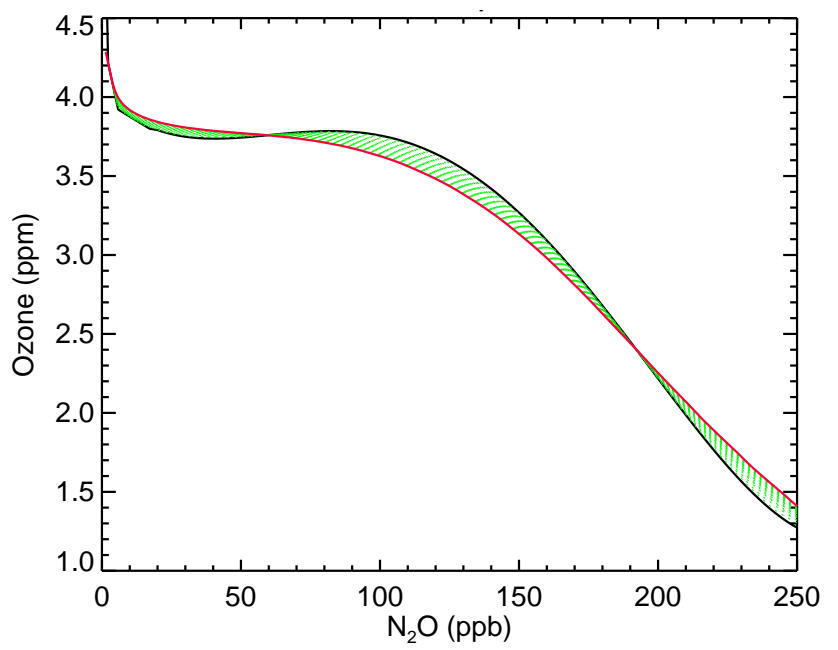

Fig. 5. The impact of differential descent on the $\mathrm{O}_{3} / \mathrm{N}_{2} \mathrm{O}$ relation in the vortex from an idealised calculation. The black solid line shows the initial $\mathrm{O}_{3} / \mathrm{N}_{2} \mathrm{O}$ relation, the red line the $\mathrm{O}_{3} / \mathrm{N}_{2} \mathrm{O}$ relation after 20 iterations of differential descent. It is assumed that one third of the vortex air mass descends twice as much as the rest of the vortex air mass, followed by instantaneous horizontal mixing (see text for details). The green dotted lines show the gradual change of the $\mathrm{O}_{3} / \mathrm{N}_{2} \mathrm{O}$ relation with each timestep.

Here, we conduct a rather simple calculation to assess the impact of differential descent on ozone-tracer relationships in the polar vortex. We consider idealised conditions: the vortex is described by a single column of air and the vertical coordinate is the potential temperature $\theta$. In a given timestep $\Delta t$ the main vortex air mass descends by $\Delta \theta$, with a fraction $\alpha$ of the vortex air mass assumed to be descending (unmixed) by $\delta \Delta \theta$ with $\delta>1$. The vortex air mass is then assumed to be immediately homogenised by horizontal mixing. This procedure is repeated $n$ times with the intention of approximately describing the development of the vortex over a winter season.

For the vortex air mass typical vertical profiles of ozone and $\mathrm{N}_{2} \mathrm{O}$ are prescribed as initial conditions, resulting in an initial $\mathrm{O}_{3} / \mathrm{N}_{2} \mathrm{O}$ relation in the polar vortex (solid black line in Fig. 5). The change of this initial $\mathrm{O}_{3} / \mathrm{N}_{2} \mathrm{O}$ relation due to the action of differential descent and subsequent mixing in the vortex can then be followed. In Fig. 5, this change is shown for a rather extreme case, where $\Delta \theta=5 \mathrm{~K}, \alpha=0.33, \delta=2$ (that is, one third of the vortex air mass descends twice as much as the remaining two thirds) and the number of timesteps $n=20$. Obviously, even for such conditions, the $\mathrm{O}_{3} / \mathrm{N}_{2} \mathrm{O}$ relation is little affected by the effect of differential descent.

Ozone-tracer relations are used for calculating a proxy ozone profile from a tracer profile in late winter/early spring. If the two relations shown in Fig. 5 are used to deduce proxy ozone profiles from a late winter vortex tracer profile characterised by vertical descent, the column ozone corresponding to these profiles differs by only $\approx 2.5 \mathrm{DU}$. In a scenario

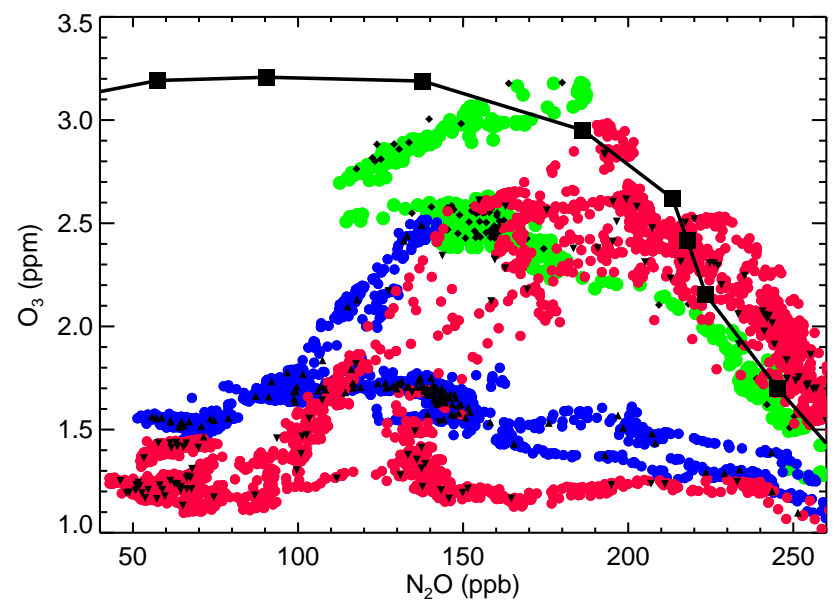

Fig. 6. The $\mathrm{O}_{3} / \mathrm{N}_{2} \mathrm{O}$ relation from measurements during winter 1999/2000. The large black squares show measurements of the MkIV instrument (Toon et al., 1999) on 3 December 1999. The coloured symbols show measurements of the NASA-ER2 aircraft on 23 January 2000 (green), 7 March 2000 (blue), and 11 March 2000 (red). Ozone measurements were made with a UV photometer (Proffitt and McLaughlin, 1983), the $\mathrm{N}_{2} \mathrm{O}$ measurements with the ALIAS (Webster et al., 1994, 23 January) and ARGUS (Loewenstein et al., 2002, 3 and 11 March) TDL instruments. Overplotted for comparison is the $\mathrm{O}_{3} / \mathrm{N}_{2} \mathrm{O}$ relation (small black symbols) based on $\mathrm{N}_{2} \mathrm{O}$ measurements by an in-situ gas chromatograph (Elkins et al., 1996) with a lower temporal resolution.

that is perhaps a bit more realistic, where $\Delta \theta=2 \mathrm{~K}, \alpha=0.33$, $\delta=1.5$ and the number of timesteps $n=50$, the corresponding difference in column ozone is less than $1 \mathrm{DU}$; the maximum change of ozone for a given tracer value due to differential descent and subsequent mixing under these conditions is $\approx 50 \mathrm{ppb}$.

This means that the contribution of the effect of differential descent to the overall uncertainty in the deduced chemical loss will be small. Given the magnitude of other sources of uncertainty, the contribution from differential descent is likely to be insignificant. This finding corroborates the conclusions of Ray et al. (2002) and Salawitch et al. (2002), who report, based on balloon measurements in winter 19992000 , that the effect of differential descent increased the uncertainty of column ozone loss estimates by $\approx 3-4 \%$.

\subsection{Impact of cross-vortex-edge mixing on ozone-tracer re- lations in the polar vortex}

Mixing across the vortex edge is usually non-local in tracertracer space and thus has the potential to alter tracer-tracer relations. The ozone-tracer relation shows greater ozone mixing ratios outside the vortex than inside (e.g., Proffitt et al., 1993; Müller et al., 2001; Rex et al., 2002; Jost et al., 2002; Tilmes et al., 2004). Mixing lines connecting inside- and outside-vortex air masses are thus expected to lie between 

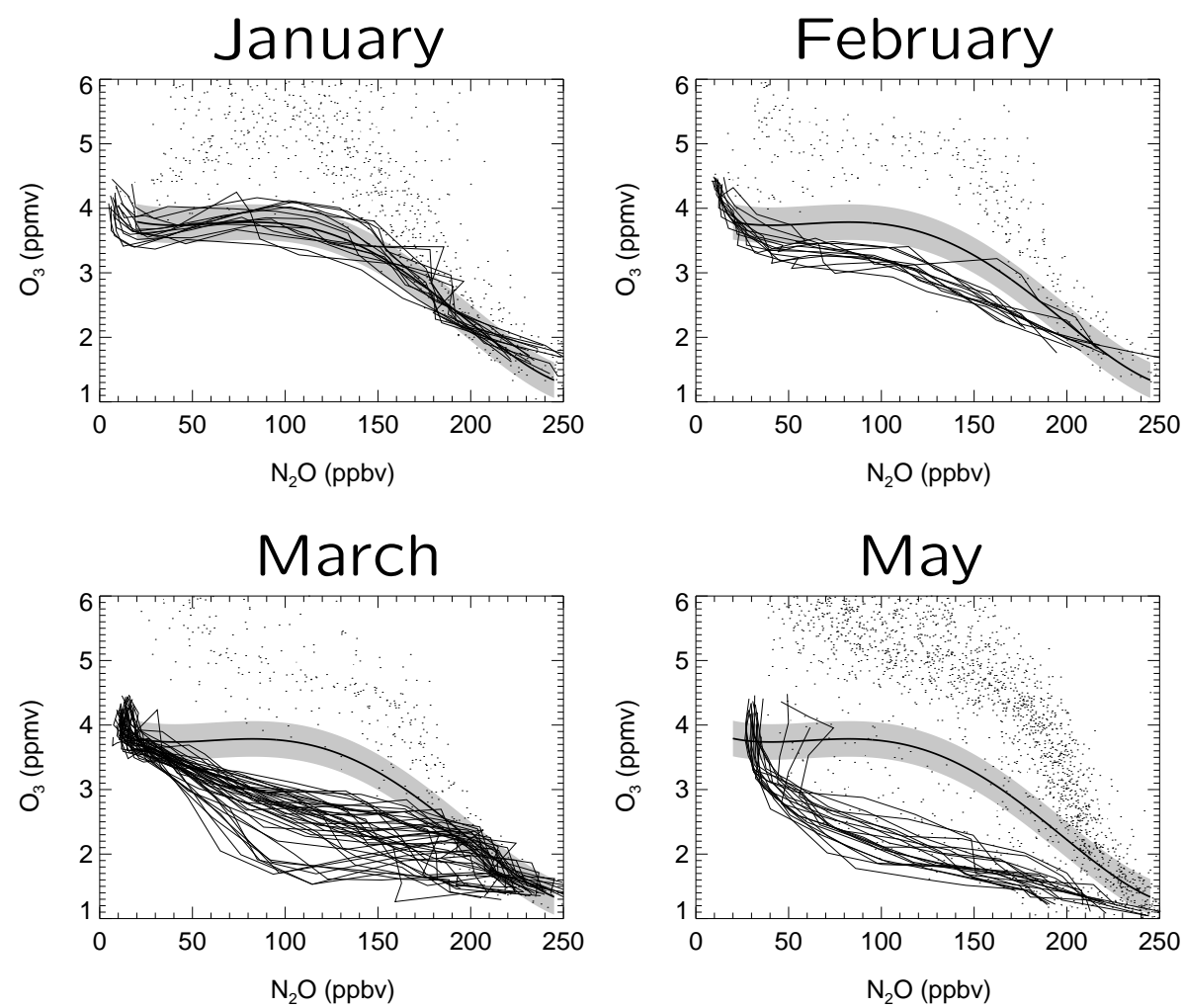

Fig. 7. The development of the $\mathrm{O}_{3} / \mathrm{N}_{2} \mathrm{O}$ relation in the Arctic in winter 1996/1997 based on ILAS measurements (Tilmes et al., 2003b). Shown are four different time periods (1-15 January, 17-21 February, 21-31 March, 1-15 May 1997). Black lines indicate profiles measured inside the polar vortex core, defined using the Nash et al. (1996) criterion. Small black dots indicate measurements outside the polar vortex. Also shown is the early vortex reference relation (thick black line, Tilmes et al., 2003b) and its uncertainty (grey shaded area). The reference is deduced from the early January ILAS measurements.

the inside and the outside vortex ozone-tracer relation (Fig. 1, top panel).

\subsubsection{Observations of mixing across the vortex edge}

Based on high altitude aircraft measurements in the Arctic in early 2000, Rex et al. (2002) and Jost et al. (2002) demonstrated that mixing across the vortex edge leads to an increase in the mixing ratio of ozone for a given value of $\mathrm{N}_{2} \mathrm{O}$. Further, Rex et al. (2002) and Ray et al. (2002) emphasise that although in this winter mixing lines were observed, entrainment of extra-vortex air did not significantly alter the composition of the vortex air between January and March 2000. Figure 6 shows an example of measurements of such mixing lines between vortex air, depleted in ozone, and outsidevortex air. The vortex air is characterised on 23 January 2000 by ozone mixing ratios up to about $2.5 \mathrm{ppm}$ (green symbols), on 7 March 2000 by ozone mixing ratios up to about $1.7 \mathrm{ppm}$ (blue symbols), and on 11 March 2000 by ozone mixing ratios of about $1.2 \mathrm{ppm}$. Clearly noticeable are the mixing lines towards air with greater ozone and greater $\mathrm{N}_{2} \mathrm{O}$ mixing ratios, that is air of mid-latitude characteristics. Clearly, there is no evidence from the measurements of mixing lines on the 'low ozone' side of the $\mathrm{O}_{3} / \mathrm{N}_{2} \mathrm{O}$ relations.

When the transport barrier at the edge of the vortex is weak, mixing is expected to noticeably influence the ozonetracer relation inside the vortex. According to the arguments above, one expects ozone to increase for a given tracer mixing ratio. This effect was indeed observed by the ILAS instrument in winter 1996-1997 (Tilmes et al., 2003b). In this winter, the vortex was perturbed by a stratospheric warming in early winter and therefore the vortex edge was permeable until late December. ILAS provided good coverage of the Arctic polar region in winter 1996-1997 covering a latitude range between $55^{\circ}-77^{\circ} \mathrm{N}$ and measuring about fourteen profiles per day. These measurements show (see Fig. 7 in Tilmes et al., 2003b) that inside the vortex ozone increased at a given $\mathrm{N}_{2} \mathrm{O}$ level in December (when the vortex was still relatively weak) and that a compact $\mathrm{O}_{3} / \mathrm{N}_{2} \mathrm{O}$ relation was established by early January (when a strong vortex had formed).

In cases where a comprehensive set of tracer measurements is available, further insight on mixing under weak vortex conditions can be obtained. Considering relations of two long-lived tracers that are curved could be used to identify 
mixing. If both tracers are chosen so that they are not subject to chemical change over the timescale in question as is the case for example with $\mathrm{CFC}-11 / \mathrm{N}_{2} \mathrm{O}$, chemical change will not interfere with the diagnosis of mixing.

Mixing across the vortex edge is likewise important for establishing the ozone tracer relation in the very early, incipient vortex. The air in high latitudes in autumn from which the polar vortex is formed, is characterised by low ozone mixing ratios, a remainder of summertime ozone loss. Because the transport barrier of the incipient vortex, while established, is still somewhat permeable, ozone-rich, mid-latitude air is mixed into the vortex. In this way, the ozone-tracer relation in the vortex recovers from summertime ozone loss. This process was first noted by Proffitt et al. (1992) and recently analysed in detail based on ILAS II measurements in the high latitudes of both hemispheres (Tilmes et al., 2005 $\mathrm{a}^{1}$ ).

\subsubsection{Cross-vortex-edge mixing in conceptual models}

Plumb et al. (2000) presented a conceptual model, a simple advective diffusive model in cylindrical geometry, to describe the impact of mixing on tracer-tracer relations. Their model simulates the effect of mixing on the relationship of two artificial tracers $\chi_{1}$ and $\chi_{2}$ that are designed to resemble $\mathrm{N}_{2} \mathrm{O}$ and $\mathrm{NO}_{\mathrm{y}}$. The relation of $\chi_{1}$ and $\chi_{2}$ is the same on both sides of a transport barrier that represents the vortex edge in the model. The typical time scale $T$ for the model is the lifetime of the vortex, say four months or $\approx 10^{7} \mathrm{~s}$, and the typical horizontal length scale $R$ is from the pole to the subtropical transport barrier, say $\approx 7 \cdot 10^{6} \mathrm{~m}$. The dimensionless diffusivity in the vortex edge region is chosen to be $K=0.05$ by Plumb et al. (2000). If this dimensionless diffusivity is converted to a dimensioned diffusivity $D$, where $D=\left(K \cdot R^{2}\right) / T$, one obtains $D \approx 3 \cdot 10^{5} \mathrm{~m}^{2} \mathrm{~s}^{-1}$.

This value may be compared with effective atmospheric diffusivities deduced from aircraft measurements $D_{\text {eff }}=5 \cdot 10^{3} \mathrm{~m}^{2} \mathrm{~s}^{-1}$ (Waugh et al., 1997) or diffusivities $\left(D=1.1 \cdot 10^{3} \mathrm{~m}^{2} \mathrm{~s}^{-1}\right)$ employed in the chemical transport model CLaMS for reproducing observed filamentary tracer structures at the polar vortex edge (Konopka et al., 2003a, 2005b). The diffusivities in the CLaMS model are the same for studies addressing rather different problems such as reproducing observed filamentary tracer structures (e.g., Khosrawi et al., 2005; Konopka et al., 2005b) or simulating the stratospheric warming in the Antarctic in September 2002 (Konopka et al., 2005a). Note that the Eulerian parametrisation of mixing in the model by Plumb et al. (2000) is different from the Lagrangian concept used in CLaMS, where the mixing intensity is proportional to the gradient of the wind rather than to the wind itself as is the case in Eulerian models.

That means, the cross vortex edge diffusivity is likely to be substantially greater in the Plumb et al. (2000) conceptual model than in the stratosphere. Therefore, conclusions based on the results of this conceptual model do not carry over directly to stratospheric conditions. A further caveat for the application of conclusions from this conceptual model to the behaviour of ozone-tracer relations in the stratospheric polar vortex is that Plumb et al. (2000) assume the same tracertracer relation inside and outside the vortex; an assumption that is not valid for the ozone-tracer relation in the polar region (Müller et al., 2001, see also discussion below).

\subsubsection{Cross-vortex mixing in a Lagrangian chemical trans- port model}

Konopka et al. $\left(2004,2005 \mathrm{c}^{3}\right)$ have shown that in the Lagrangian model CLaMS rather little exchange occurs across the polar vortex edge as long as a stable vortex exists. If exchange occurs, air masses will mix approximately along isentropic surfaces leading to an increase of ozone mixing ratios with respect to the vortex reference relation (Fig. 4). However, the lower the potential temperature level at which the mixing occurs, the less is the deviation of the isentropic surfaces from the vortex reference relation in ozone-tracer space (Fig. 4). That means, the lower down in the vortex mixing occurs, the smaller the impact of mixing events is on the ozone tracer relation (see Lemmen et al., $2005^{4}$ for a more detailed discussion of this issue).

\section{Discussion}

We have discussed here the validity of the two major hypotheses on which the use of ozone-tracer relations for deducing chemical ozone loss in the polar vortex is based, namely that a compact ozone-tracer relation is established in the 'early' polar vortex before the onset of chemical ozone loss and that any change of the ozone-tracer relation in the vortex over the course of winter is mainly caused by chemical ozone loss.

Based on both measurements in the polar stratosphere and model results, we argue that a compact ozone-tracer relation develops within the polar vortex. Model results (Sankey and Shepherd, 2003) showing no compact ozone-tracer relation in the Arctic vortex and a rather slow development of compactness of the ozone-tracer relation in the Antarctic vortex are likely caused by an insufficient representation of the transport barrier at the vortex edge in the model employed.

Recently, Konopka et al. (2004) analysed the development of ozone-tracer relations in simulations of the Lagrangian model CLaMS (McKenna et al., 2002b), a model in which a strong transport barrier develops at the edge of the polar vortex (e.g. Konopka et al., 2003b, 2004; Steinhorst et al., 2005). Compact ozone-tracer relations are found in the CLaMS results between simulated tracer $\left(\mathrm{CH}_{4}\right)$ and passive ozone mixing ratios in the Antarctic vortex for September to November

\footnotetext{
${ }^{4}$ Lemmen, C., Müller, R., Konopka, P., and Dameris, M.: Tracer-tracer relations as a tool for analyzing polar chemical ozone loss in chemistry-climate models, J. Geophys. Res., submitted, 2005.
} 
2002 (Konopka et al., 2004). Compact correlations are likewise found for the ozone-tracer relation, when ozone is deduced from POAM satellite measurements interpolated to the CLaMS model grid points. Similarly, CLaMS model simulations for the mid-winter Arctic vortex (Fig. 4, Konopka et al., $2005 \mathrm{c}^{3}$ ) show both a clear separation between mid-latitude and vortex air masses and a compact ozone-tracer relation within the vortex.

Indeed, HALOE measurements in the Arctic vortex in January 1992 show a compact ozone-tracer relation (Fig. 3). The same is true for ILAS measurements in the Arctic vortex in January 1997 which provide a better coverage of the vortex (Fig. 7, see also Tilmes et al., 2003b).

Reference relations for deducing ozone loss that are derived from mixing lines (Michelsen et al., 1998) yield results for the deduced chemical ozone loss comparable to those obtained by using an 'early vortex' relation from within the vortex. Nonetheless, we consider an 'early vortex' relation as a more reliable reference than one derived from mixing lines.

Inside- and outside-vortex air is characterised by different ozone-tracer relationships, with the outside-vortex relationships showing greater ozone mixing ratios (and a stronger variability) for equal values of the tracer than inside relationships (e.g., Proffitt et al., 1990; Müller et al., 1999, 2002; Tilmes et al., 2003b). Consequently, mixing between air masses inside and outside the vortex should lead to points lying above the original ozone-tracer relation in the vortex (Fig. 1, top panel), as has been indeed observed in Arctic winter 2000 (Rex et al., 2002; Jost et al., 2002, see also Fig. 6).

Therefore, mixing across the vortex edge, if it occurs during the period of chemical ozone loss, should lead to an 'underestimation' of ozone loss. This finding is in contrast to the conclusions of Plumb et al. (2000), who state that 'estimates of ozone depletion inferred from ozone-tracer relations are likely to be overestimates'. We argue here that this different conclusion is reached by Plumb et al. (2000) because they assume the same tracer-tracer relation inside and outside the vortex and use a rather high diffusivity at the vortex edge in their conceptual model.

Simulations with the Lagrangian model CLaMS (Konopka et al., 2004, 2005 $\mathrm{c}^{3}$; Lemmen et al., 2005 ${ }^{4}$ ) indicate that if exchange across the transport barrier at the vortex edge occurs, it will lead to an increase of ozone mixing ratios in the vortex. Further, as air masses will mix approximately along isentropic surfaces crossing the vortex edge, mixing will have an increasingly smaller impact on the ozone tracer relation in the vortex, the lower down a mixing event occurs (Fig. 4). Indeed, Jost et al. (2002) report a case where mixing across the vortex edge occurred at $\approx 380 \mathrm{~K}$ in early March of Arctic winter 2000 that did not noticeably change the $\mathrm{O}_{3} / \mathrm{N}_{2} \mathrm{O}$ relation.

Esler and Waugh (2002) proposed to construct an artificial reference tracer from a linear combination of several longlived tracers so that a linear relation of a chemically active tracer with the artificial reference tracer would result. In this way, the impact of a mixing event of the type shown in Fig. 1, bottom panel, can be removed from the analysis since linear tracer-tracer relationships are unaffected by such mixing events. However, since inside- and outside-vortex air is characterised by different ozone-tracer relationships, the construction of an artificial reference tracer as suggested by Esler and Waugh (2002) (for estimating denitrification) would not help to eliminate the impact of mixing between inside- and outside-vortex air masses on ozone-tracer relations inside the polar vortex.

Differential descent within the vortex with subsequent horizontal mixing results in mixing events of the type shown in Fig. 1, bottom panel. We have shown here that over the lifetime of the polar vortex this mechanism can only have a minor impact on ozone-tracer relations within the vortex (Fig. 5), corroborating conclusions based on measurements in winter 1999/2000 (Ray et al., 2002; Salawitch et al., 2002).

In any event, if chemical ozone loss in the polar vortex occurs, it will reduce ozone mixing ratios in the vortex and thus it will alter the reference ozone-tracer relation. In winter 1996/97 (Fig. 7), the beginning ozone depletion is clearly noticeable as a moderate deviation of the ozone-tracer relation from the reference relation. In late March, after substantial ozone loss, a strong deviation from the reference relation is obvious. The ozone-tracer relation in March is 'not' compact because of a chemical reason, namely substantially different chemical ozone loss in different parts of the polar vortex (McKenna et al., 2002a; Tilmes et al., 2003b). In early May 1997, compact ozone-tracer relations were again observed in the remaining vortex, consistent with the view that mixing in the vortex had, by that time, homogenised the vortex air mass again.

The chemical ozone loss deduced using the TRAC method has been compared with the results of other methods (Harris et al., 2002; Tilmes et al., 2004). The results deduced using tracer-tracer relations are in general agreement with those obtained by other methods; however, the very strong ozone loss deduced from SAOZ measurements for January in some winters (e.g., Goutail et al., 1999) cannot be identified with TRAC.

\section{Conclusions}

Ozone-tracer relations have been used for more than a decade to quantify chemical ozone loss in the polar vortex. An issue neglected in the early studies is that it is necessary to assess the impact of mixing processes on tracer-tracer relationships in the polar vortex for a reliable quantification of ozone loss. Recently, also the question of the behaviour of ozone-tracer correlations in the results of model simulations has attracted interest.

Analysing various sets of measurements and the results from several models we find here that mixing across the 


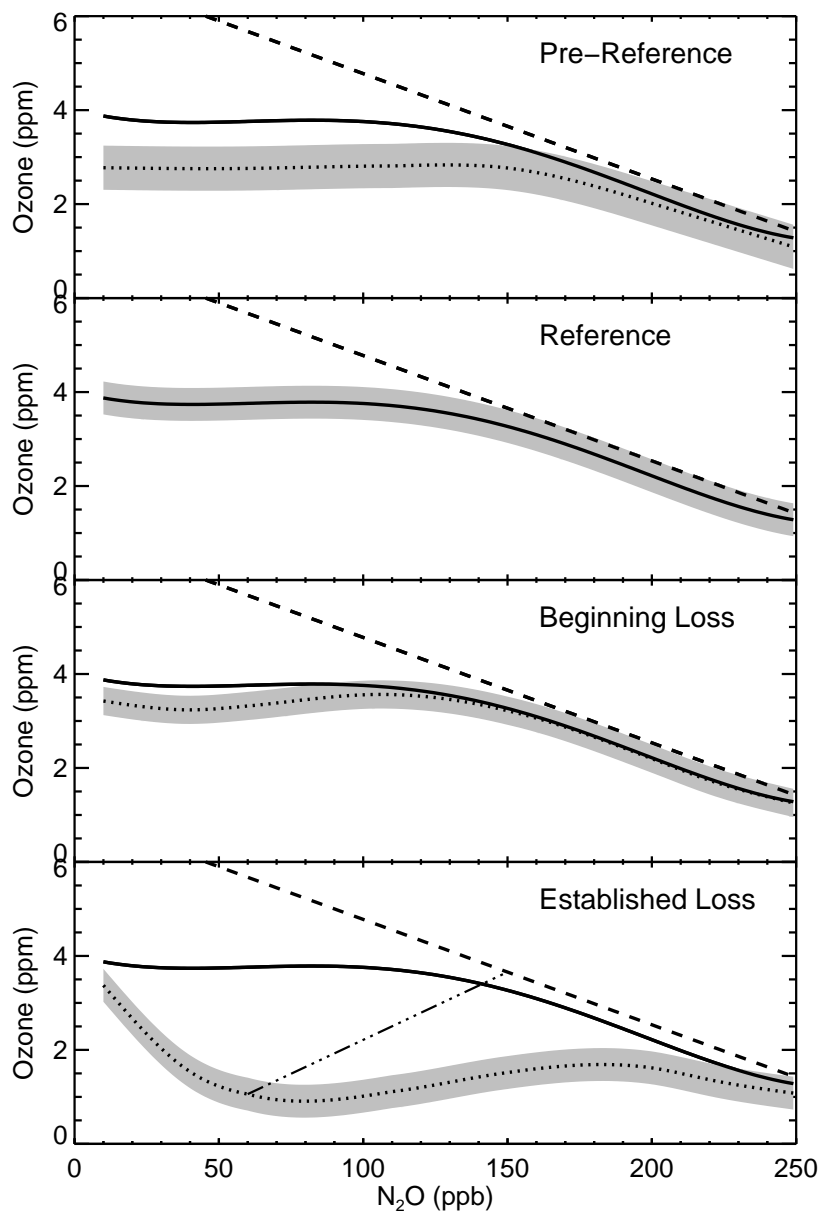

Fig. 8. Schematic view of the development of ozone-tracer relations over the course of the winter inside the polar vortex. In all panels, the thick solid line indicates the reference relation for 'early vortex' conditions and the thick dashed line an average mid-latitude relation. The grey shaded area indicates schematically the variability of the ozone-tracer relations within the vortex. The dotted line in the top panel shows the ozone-tracer relation in the incipient vortex, before a strong transport barrier is established at the vortex edge. The panel below shows the reference relation for an established vortex and one panel below the ozone-tracer relation for beginning chemical ozone loss. The bottom panel shows the conditions for established ozone loss, the dash-dotted line indicates a possible mixing line between vortex and out-of-vortex air.

vortex edge can only lead to an 'underestimation' of ozone loss and not to an overestimation as has been suggested. Further, differential descent within the vortex and the subsequent internal mixing has only a negligible impact on ozone loss estimates.

Moreover, the representation of mixing in threedimensional atmospheric models can have a substantial impact on the development of tracer relations in the model. Of particular importance is a realistic representation of transport barriers (such as the polar vortex edge) in the model. Rather compact ozone-tracer relations develop - in agreement with observations - in the vortex of a Lagrangian model (CLaMS) where mixing is anisotropic and driven by the deformation of the flow.

Drawing together all the pieces of information considered here, the following picture emerges of the development of ozone-tracer relations in the polar vortex develops (Fig. 8). In the incipient vortex the vortex air mass is characterised by low ozone mixing ratios; the result of polar ozone destruction due to $\mathrm{NO}_{\mathrm{x}}$-driven chemical cycles in summer (e.g., Farman, 1985) and autumn (Kawa et al., 2002; Tilmes et al., 2005 $\mathrm{a}^{1}$ ). Although the vortex air mass is separated to a certain extent from ozone-rich, mid-latitude air, the vortex is not yet completely isolated. Thus, through mixing, ozone values in the vortex increase during this period (Tilmes et al., 2003b, 2005b). When the vortex is well established, the transport barrier at the vortex edge effectively separates the vortex air from mid-latitude air. Mixing within the vortex air mass produces a compact ozone-tracer relation in the vortex. This is the point in time when the reference relation for the TRAC method should ideally be derived.

In cold winters, a beginning chemical ozone loss first becomes noticeable at greater altitudes $(\approx 500 \mathrm{~K})$, typically in late January/early February in the Arctic (Tilmes et al., 2003b). Towards late winter, with solar illumination strongly increasing, the ozone loss is accelerated. Thus, in early spring, there is a pronounced signal of accumulated ozone loss in the ozone-tracer relation (Fig. 8, bottom panel). Under such conditions, mixing across the vortex edge clearly leads to an underestimate of ozone loss.

We conclude that when using ozone-tracer relations to deduce chemical ozone loss, it is crucial that a reliable "early vortex' reference can be obtained and that vortex measurements are well separated from mid-latitude measurements. If these conditions are met, ozone-tracer relations constitute a reliable tool for the quantitative determination of chemical ozone loss in the polar vortex.

Acknowledgements. We thank D. Sankey, T. S. Shepherd, and C. Lemmen for fruitful discussions and for helpful comments on the paper. Further, we thank J. W. Elkins for the ACATS data, E. Richard for the ozone photometer data, G. C. Toon for the MkIV data, C. R. Webster for the ALIAS data, and J. M. Russell III and the HALOE team for the HALOE (v19) data.

Edited by: M. Dameris 


\section{References}

Elkins, J. W., Fahey, D. W., Gilligan, J. M., Dutton, G. S., Baring, T. J., Volk, C. M., Dunn, R. E., Myers, R. C., Montzka, S. A., Wamsley, P. R., Hayden, A. H., Butler, J. H., Thompson, T. M., Swanson, T. H., Dlugokencky, E. J., Novelli, P. C., Hurst, D. F., Lobert, J. M., Ciciora, S. J., McLaughlin, R. J., Thompson, T. L., Winkler, R. H., Fraser, P. J., Steele, L. P., and Lucarelli, M. P.: Airborne gas chromatograph for in situ measurements of longlived species in the upper troposphere and lower stratosphere, Geophys. Res. Lett., 23(4), 347-350, doi:10.1029/96GL00244, 1996.

Esler, J. G. and Waugh, D. W.: A method for estimating the extent of denitrification of Arctic polar vortex air from tracer-tracer scatter plots, J. Geophys. Res., 107(6), 1-14, doi:10.1029/2001JD001071, 2002.

Fahey, D. W., Kelly, K. K., Kawa, S. R., Tuck, A. F., Loewenstein, M., Chan, K. R., and Heid, L. E.: Observations of denitrification and dehydration in the winter polar stratosphere, Nature, 344, 321-324, 1990.

Farman, J. C.: Ozone photochemistry in the Antarctic stratosphere in summer, Q. J. R. Meteorol. Soc., 111, 1013-1025, 1985.

Goutail, F., Pommereau, J.-P., Phillips, C., Deniel, C., Sarkssian, A., Lefèvre, F., Kyrö, E., Rummukainen, M., Ericksen, P., Andersen, S. B., Kaastad-Hoiskar, B.-A., Braathen, G., Dorokhov, V., and Khattatov, V. U.: Depletion of Column Ozone in the Arctic during the winter of 1993-94 and 1994-95, J. Atmos. Chem., 32, 1-34, 1999.

Harris, N. R., Rex, M., Goutail, F., Knudsen, B. M., Manney, G. L., Müller, R., and von der Gathen, P.: Comparison of empirically derived ozone loss rates in the Arctic vortex, J. Geophys. Res., 107(D20), doi:10.1029/2001JD000482, 2002.

Jost, H.-J., Loewenstein, M., Greenblatt, J. G., Podolske, J. R., Bui, T. P., Hurst, D. F., Elkins, J. W., Herman, R. L., Webster, C. R., Schauffler, S. M., Atlas, E. L., Newman, P. A., Lait, L., and Wofsy, S. C.: Mixing events revealed by anomalous tracer relationships in the Arctic vortex during winter 1999/2000, J. Geophys. Res., 107, 4795, doi:10.1029/2002JD002380, 2002.

Kawa, S. R., Bevilacqua, R. M., Margitan, J. J., Douglass, A. R., Schoeberl, M. R., Hoppel, K. W., and Sen, B.: Interaction between dynamics and chemistry of ozone in the setup phase of the Northern Hemisphere polar vortex, J. Geophys. Res., 108, 8310, doi:10.1029/2001JD001527, 2002.

Khosrawi, F., Müller, R., Proffitt, M., and Nakajima, H.: Monthly averaged ozone and nitrous oxide from the Improved Limb Atmospheric Spectrometer (ILAS) in the Northern and Southern Hemisphere polar regions, J. Geophys. Res., 109, D10301, doi:10.1029/2003JD004365, 2004.

Khosrawi, F., Grooß, J.-U., Müller, R., Konopka, P., Kouker, W., Ruhnke, R., Reddmann, T., and Riese, M.: Intercomparison between Lagrangian and Eulerian simulations of the development of mid-latitude streamers as observed by CRISTA, Atmos. Chem. Phys., 5, 85-95, 2005,

SRef-ID: 1680-7324/acp/2005-5-85.

Konopka, P., Grooß, J.-U., Bausch, S., Müller, R., McKenna, D. S., Morgenstern, O., and Orsolini, Y.: Dynamics and chemistry of vortex remnants in late Arctic spring 1997 and 2000: Simulations with the Chemical Lagrangian Model of the Stratosphere (CLaMS), Atmos. Chem. Phys., 3, 839-849, 2003a,

SRef-ID: 1680-7324/acp/2003-3-839.
Konopka, P., Grooß, J. U., Günther, G., McKenna, D. S., Müller, R., Elkins, J. W., Fahey, D., and Popp, P.: Weak impact of mixing on chlorine deactivation during SOLVE/THESEO2000: Lagrangian modeling (CLaMS) versus ER-2 in situ observations, J. Geophys. Res., 108, 8324, doi:10.1029/2001JD000876, 2003 b.

Konopka, P., Steinhorst, H.-M., Grooß, J.-U., Günther, G., Müller, R., Elkins, J. W., Jost, H.-J., Richard, E., Schmidt, U., Toon, G., and McKenna, D. S.: Mixing and Ozone Loss in the 1999-2000 Arctic Vortex: Simulations with the 3-dimensional Chemical Lagrangian Model of the Stratosphere (CLaMS), J. Geophys. Res., 109, D02315, doi:10.1029/2003JD003792, 2004.

Konopka, P., Grooß, J.-U., Hoppel, K., Steinhorst, H.-M., and Müller, R.: Mixing and chemical ozone loss during and after the Antarctic polar vortex major warming in September 2002, J. Atmos. Sci., 62(3), 848-859, 2005a.

Konopka, P., Günther, G., McKenna, D. S., Müller, R., Offermann, D., Spang, R., and Riese, M.: How homogeneous and isotropic is stratospheric mixing? Comparison of CRISTA-1 observations with transport studies based on the Chemical Lagrangian Model of the Stratosphere (CLaMS), Q. J. R. Meteorol. Soc., 131(606), 565-579, doi:10.1256/qj.04.47, 2005b.

Loewenstein, M., Jost, H., Grose, J., Eilers, J., Lynch, D., Jensen, S., and Marmie, J.: Argus: A new instrument for the measurement of the stratospheric dynamical tracers, $\mathrm{N}_{2} \mathrm{O}$ and $\mathrm{CH}_{4}$, Spectrochimica Acta Part A-Molecular and Biomolecular Spectroscopy, 58(11), 2329-2345, 2002.

McKenna, D. S., Grooß, J.-U., Günther, G., Konopka, P., Müller, R., Carver, G., and Sasano, Y.: A new Chemical Lagrangian Model of the Stratosphere (CLaMS): Part II Formulation of chemistryscheme and initialisation, J. Geophys. Res., 107(D15), 4256, doi:10.1029/2000JD000113, 2002a.

McKenna, D. S., Konopka, P., Grooß, J.-U., Günther, G., Müller, R., Spang, R., Offermann, D., and Orsolini, Y.: A new Chemical Lagrangian Model of the Stratosphere (CLaMS): Part I Formulation of advection and mixing, J. Geophys. Res., 107(D16), 4309, doi:10.1029/2000JD000114, 2002b.

Michelsen, H. A., Manney, G. L., Gunson, M. R., and Zander, R.: Correlations of stratospheric abundances of $\mathrm{NO}_{\mathrm{y}}, \mathrm{O}_{3}, \mathrm{~N}_{2} \mathrm{O}$, and $\mathrm{CH}_{4}$ derived from ATMOS measurements, J. Geophys. Res., 103, 28 347-28359, 1998.

Müller, R.: The performance of classical versus modern finitevolume advection schemes for atmospheric modelling in a onedimensional test-bed, Mon. Wea. Rev., 120, 1407-1415, 1992.

Müller, R., Crutzen, P. J., Grooß, J.-U., Brühl, C., Russel III, J. M., and Tuck, A. F.: Chlorine activation and ozone depletion in the Arctic vortex: Observations by the Halogen Occultation Experiment on the Upper Atmosphere Research Satellite, J. Geophys. Res., 101, 12 531-12 554, 1996.

Müller, R., Grooß, J.-U., McKenna, D. S., Crutzen, P. J., Brühl, C., Russell, J. M., and Tuck, A. F.: HALOE observations of the vertical structure of chemical ozone depletion in the Arctic vortex during winter and early spring 1996-1997, Geophys. Res. Lett., 24, 2717-2720, 1997.

Müller, R., Grooß, J.-U., McKenna, D. S., Crutzen, P. J., Brühl, C., Russell, J. M., Gordley, L. L., Burrows, J. P., and Tuck, A. F.: Chemical ozone loss in the Arctic vortex in the winter 19951996: HALOE measurements in conjunction with other observations, Ann. Geophys., 17, 101-114, 1999,

SRef-ID: 1432-0576/ag/1999-17-101. 
Müller, R., Schmidt, U., Engel, A., McKenna, D. S., and Proffitt, M. H.: The $\mathrm{O}_{3} / \mathrm{N}_{2} \mathrm{O}$ relationship from balloon-borne observations as a measure of Arctic ozone loss in 1991-1992, Q. J. R. Meteorol. Soc., 127, 1389-1412, 2001.

Müller, R., Tilmes, S., Grooß, J.-U., McKenna, D. S., Müller, M., Schmidt, U., Toon, G. C., Stachnik, R. A., Margitan, J. J., Elkins, J. W., Arvelius, J., and Russell III, J. M.: Chlorine Activation and Chemical Ozone Loss Deduced from HALOE and Balloon Measurements in the Arctic during the Winter of 1999-2000, J. Geophys. Res., 107, 8302, doi:10.1029/2001JD001423, 2002.

Nash, E. R., Newman, P. A., Rosenfield, J. E., and Schoeberl, M. R.: An objective determination of the polar vortex using Ertel's potential vorticity, J. Geophys. Res., 101, 9471-9478, 1996.

Plumb, R. A.: Stratospheric transport, J. Meteorol. Soc. Jpn., 80(4B), 793-809, 2002.

Plumb, R. A. and Ko, M. K. W.: Interrelationships between mixing ratios of long-lived stratospheric constituents, J. Geophys. Res., 97, 10 145-10 156, 1992.

Plumb, R. A., Waugh, D. W., and Chipperfield, M. P.: The effect of mixing on tracer relationships in the polar vortices, J. Geophys. Res., 105, 10 047-10 062, 2000.

Proffitt, M. H. and McLaughlin, R. J.: Fast-response dual-beam UV absorption ozone photometer suitable for use on stratospheric balloons, Rev. Sci. Instr., 54, 1719-1728, 1983.

Proffitt, M. H., Margitan, J. J., Kelly, K. K., Loewenstein, M., Podolske, J. R., and Chan, K. R.: Ozone loss in the Arctic polar vortex inferred from high altitude aircraft measurements, Nature, 347, 31-36, 1990.

Proffitt, M. H., Solomon, S., and Loewenstein, M.: Comparison of 2-D model simulations of ozone and nitrous oxide at high latitudes with stratospheric measurements, J. Geophys. Res., 97, 939-944, 1992.

Proffitt, M. H., Aikin, K., Margitan, J. J., Loewenstein, M., Podolske, J. R., Weaver, A., Chan, K. R., Fast, H., and Elkins, J. W.: Ozone loss inside the northern polar vortex during the 1991-1992 winter, Science, 261, 1150-1154, 1993.

Proffitt, M. H., Aikin, K., Tuck, A. F., Margitan, J. J., Webster, C. R., Toon, G. C., and Elkins, J. W.: Seasonally averaged ozone and nitrous oxide in the northern hemisphere lower stratosphere, J. Geophys. Res., 108, 4110, doi:10.1029/2002JD002657, 2003.

Ray, E. A., Moore, F. L., Elkins, J. W., Hurst, D. F., Romashkin, P. A., Dutton, G. S., and Fahey, D. W.: Descent and mixing in the 1999-2000 northern polar vortex inferred from in situ tracer measurements, J. Geophys. Res., 107, 8285, doi:10.1029/2001JD000961, 2002.

Rex, M., Salawitch, R. J., Harris, N. R. P., von der Gathen, P., Schulz, G. O. B. A., Deckelman, H., Chipperfield, M., Sinnhuber, B.-M., Reimer, E., Alfier, R., Bevilacqua, R., Hoppel, K., Fromm, M., Lumpe, J., Küllmann, H., Kleinböhl, A., von König, H. B. M., Künzi, K., Toohey, D., Vömel, H., Richard, E., Aiken, K., Jost, H., Greenblatt, J. B., Loewenstein, M., Podolske, J. R., Webster, C. R., Flesch, G. J., Scott, D. C., Herman, R. L., Elkins, J. W., Ray, E. A., Moore, F. L., Hurst, D. F., Romanshkin, P., Toon, G. C., Sen, B., Margitan, J. J., Wennberg, P., Neuber, R., Allart, M., Bojkov, B. R., Claude, H., Davies, J., Davies, W., De Backer, H., Dier, H., Dorokhov, V., Fast, H., Kondo, Y., Kyrö, E., Litynska, Z., Mikkelsen, I. S., Molyneux, M. J., Moran, E., Nagai, T., Nakane, H., Parrondo, C., Ravegnani, F., Viatte, P. S. P., and Yushkov, V.: Chemical depletion of Arc- tic ozone in winter 1999/2000, J. Geophys. Res., 107, 8276, doi:10.1029/2001JD000533, 2002.

Richard, E. C., Aikin, K. C., Andrews, A. E., Daube, B. C., Gerbig, C., Wofsy, S. C., Romashkin, P. A., Hurst, D. F., Ray, E. A., Moore, F. L., Elkins, J. W., Deshler, T., and Toon, G. C.: Severe chemical ozone loss in the Arctic polar vortex during winter 1999-2000 inferred from in-situ airborne measurements, Geophys. Res. Lett., 28(11), 2197-2000, 2001.

Roach, W. T.: Aircraft observations in the lower sub-Arctic stratosphere in winter, Meteorol. Res. Comm. Pap., 121, 1962.

Robinson, A. D., Millard, G. A., Danis, F., Guirlet, M., Harris, N. R. P., Lee, A. M., McIntyre, J. D., Pyle, J. A., Arvelius, J., Dagnesjo, S., Kirkwood, S., Nilsson, H., Toohey, D. W., Deshler, T., Goutail, F., Pommerau, J.-P., Elkins, J. W., Moore, F., Ray, E., Schmidt, U., Engel, A., and Müller, M.: Ozone loss derived from balloon-borne tracer measurements in the 1999/2000Arctic winter, Atmos. Chem. Phys., 5, 1423-1436, 2005,

SRef-ID: 1680-7324/acp/2005-5-1423.

Rood, R. B.: Numerical advection algorithms and their role in atmospheric transport and chemistry models, Rev. Geophys., 25(1), 71-100, 1987

Ross, D., Pyle, J., Harris, N., McIntyre, J., Millard, G., Robinson, A., and Busen, R.: Investigation of Arctic ozone depletion sampled over midlatitudes during the Egrett campaign of spring/summer 2000, Atmos. Chem. Phys., 4, 1407-1417, 2004, SRef-ID: 1680-7324/acp/2004-4-1407.

Russell, J. M., Gordley, L. L., Park, J. H., Drayson, S. R., Tuck, A. F., Harries, J. E., Cicerone, R. J., Crutzen, P. J., and Frederick, J. E.: The Halogen Occultation Experiment, J. Geophys. Res., 98, 10777-10 797, 1993.

Salawitch, R. J., Margitan, J., Sen, B., Toon, G. C., Osterman, G. B., Rex, M., Elkins, J. W., Ray, E. A., Moore, F. L., Hurst, D. F., Romashkin, P. A., Bevilacqua, R. M., Hoppel, K., Richard, E. C., and Bui, T. P.: Chemical loss of ozone during the Arctic winter of 1999-2000: an analysis based on balloon-borne observations, J. Geophys. Res., 107(D20), 8269, doi:10.1029/2001JD000620, 2002.

Sankey, D. and Shepherd, T. G.: Correlations of long-lived chemical species in a middle atmosphere general circulation model, J. Geophys. Res., 108(D16), 4494, doi:10.1029/2002JD002799, 2003.

Sasano, Y., Suzuki, M., Yokota, T., and Kanzawa, H.: Improved Limb Atmospheric Spectrometer (ILAS) for stratospheric ozone layer measurements by solar occultation technique, Geophys. Res. Lett., 26, 197-200, doi:10.1029/1998GL900276, 1999.

Steinhorst, H.-M., Konopka, P., Günther, G., and Müller, R.: How permeable is the edge of the Arctic vortex - Model studies of the winter 1999-2000, J. Geophys. Res., 110, D06105, doi:10.1029/2004JD005268, 2005.

Thuburn, J. and McIntyre, M.: Numerical advection schemes, cross-isentropic random walks, and correlations between chemical species, J. Geophys. Res., 102(D6), 6775-6797, 1997.

Tilmes, S.: Chemical ozone loss in the Arctic polar stratosphere, Tech. rep., Institute for Chemistry and Dynamics of the Geosphere, Jülich, Germany, 2004.

Tilmes, S., Müller, R., Grooß, J.-U., Höpfner, M., Toon, G. C., and Russell, J. M.: Very early chlorine activation and ozone loss in the Arctic winter 2002-2003, Geophys. Res. Lett., 30(23), 2201, doi:10.1029/2003GL018079, 2003a. 
Tilmes, S., Müller, R., Grooß, J.-U., McKenna, D. S., Russell, J. M., and Sasano, Y.: Calculation of chemical ozone loss in the Arctic winter 1996-1997 using ozone-tracer correlations: Comparison of Improved Limb Atmospheric Spectrometer (ILAS) and Halogen Occultation Experiment (HALOE) results, J. Geophys. Res., 108, 4045, doi:10.1029/2002JD002213, 2003b.

Tilmes, S., Müller, R., Grooß, J.-U., and Russell, J. M.: Ozone loss and chlorine activation in the Arctic winters 1991-2003 derived with the tracer-tracer correlations, Atmos. Chem. Phys., 4(8), 2181-2213, 2004,

\section{SRef-ID: 1680-7324/acp/2004-4-2181.}

Tilmes, S., Müller, R., Grooß, J.-U., Spang, R., Sugita, T., Nakajima, H., and Sasano, Y.: Chemical ozone loss and related processes in the Antarctic winter 2003 based on ILAS II observations, J. Geophys. Res., accepted, 2005b.

Toon, G. C., Blavier, J.-F., Sen, B., Margitan, J. J., Webster, C. R., May, R. D., Fahey, D., Gao, R., Del Negro, L., Proffitt, M., Elkins, J. W., Romashkin, P. A., Hurst, D. F., Oltmans, S., Atlas, E., Schauffler, S., Flocke, F., Bui, T. P., Stimpfle, R. M., Bonne, G. P., Voss, P. B., and Cohen, R. C.: Comparison of MkIV balloon and ER-2 aircraft measurements of atmospheric trace gases, J. Geophys. Res., 104, 26 779-26 790, 1999.

Ulanovskii, A. E., Luk'yanov, A. N., Yushkov, V. A., Sitnikov, N. M., Volk, M., Ivanova, E. V., and Ravegnani, F.: Estimation of the chemical loss of ozone in the Antarctic stratosphere in the 1999 winter-spring season from direct measurements and simulations, Izv. Atmos. Ocean. Phys., 40(6), 695-703, 2004.
Vogel, B., Müller, R., Deshler, T., Grooß, J.-U., Karhu, J., McKenna, D. S., Müller, M., Toohey, D., Toon, G. C., and Stroh, F.: Vertical profiles of activated $\mathrm{ClO}$ and ozone loss in the Arctic vortex in January and March 2000: In situ observations and model simulations, J. Geophys. Res., 108(D22), 8334, doi:10.1029/2002JD002564, 2003.

Volk, C. M., Elkins, J. W., Fahey, D. W., Salawitch, R. J., Dutton, G. S., Gilligan, J. M., Proffitt, M. H., Loewenstein, M., Podolske, J. R., Minschwaner, K., Margitan, J. J., and Chan, K. R.: Quantifying transport between the tropical and mid-latitude lower stratosphere, Science, 272, 1763-1768, 1996.

Waugh, D. W., Plumb, R. A., Elkins, J. W., Fahey, D. W., Boering, K. A., Dutton, G. S., Volk, C. M., Keim, E., Gao, R.-S., Daube, B. C., Wofsy, S. C., Loewenstein, M., Podolske, J. R., Chan, K. R., Proffitt, M. H., Kelly, K. K., Newman, P. A., and Lait, L. R.: Mixing of polar vortex air into middle latitudes as revealed by tracer-tracer scatterplots, J. Geophys. Res., 102, 13 119-13 134, 1997.

Webster, C. R., May, R. D., Trimble, C. A., Chave, R. G., and Kendall, J.: Aircraft laser infrared absorption spectrometer (ALIAS) for in situ atmospheric measurements of $\mathrm{HCl}, \mathrm{N}_{2} \mathrm{O}$, $\mathrm{CH}_{4}, \mathrm{NO}_{2}$, and $\mathrm{HNO}_{3}$, Appl. Opt., 33, 454-472, 1994. 